\title{
Prevalence of undernutrition among musahar children aged between 12 to 59 months in urban siraha district, Nepal
}

\begin{abstract}
Childhood is the most vulnerable phase in the life of human being; nutritional inadequacies result in hampering the growth of the body and mind. Musahar community are most deprived and fall under untouchable caste among Hindu caste hairarchy system. Descriptive cross- sectional study was conducted to assess nutritional status of under-five age children of musahar community of urban Siraha District, Nepal. Simple random sampling technique was adopted to select children for the assessment. A structured questionnaire was used to collect data from 255 children paired with their mothers. Anthropometric measurements and basic associated factors were collected. SPSS version 16.0 and WHO Anthro 3.2.2 version were used for data analysis. Bivariate and multivariate logistic regression analyses were conducted to assess factors associated to nutritional status of children. Statistical association was declared. Out of 255 musahar children, $47 \%, 36 \%$ and $21 \%$ of them were stunted, underweight, and wasted respectively. All three types of undernutrition were prevalence among $10 \%$ of total children. According to WHO Classification for assessing severity of malnutrition by prevalence ranges among children under-five years of age, the stunting, wasting and underweight rate were classified as very high. The study found significant difference in stunting with sex, socioeconomic status and age of child where as wasting was not found statistically significant with sex of the children. Musahar community had $65 \%$ children who had at least one kind of under-nutrition. Out of them, nearly half children were in critical condition (below -3SD) and they need immediate intervention. Key Words: Stunting, wasting, underweight, Musahar community.
\end{abstract}

Volume 4 Issue 5 - 2016

\author{
Sanjeev Kumar Shah, Sudeep Kumar Shetty, \\ Devendra Raj Shingh, Jennifer Mathias, \\ Abinash Upadhyay, Ramanad Pandit \\ K S Hegde Medical Academy, Nita University, India
}

Correspondence: Sanjeev Kumar Shah, K S Hegde Medical Academy, Nitte University, Managlore, India, Tel +91895I49385I, Email just4sanjeev@gmail.com

Received: May 12, 2016 | Published: June 18, 2016

\section{Introduction}

Undernutrition among children is a key public health problem in developing countries including Nepal. ${ }^{1-3}$ More than 26,000 underfive children die around the world each day mostly conditions due to escapable causes. Nearly all of them live in developing countries or, more specifically in 60 developing countries. ${ }^{4}$ Every year 7.6 million under-five children die such preventable malnutrition and its related causes. Similarly, next prevalent cause of under-five mortality is low birth weight which leads to the intergeneration cycle of malnutrition especially in female., ${ }^{5,6} \mathrm{~A}$ child's entire life is determined in huge measures by the food given to him during his first five years. Childhood is a period of fast growth and development, and nutrition is one of the influencing factors in this period.?

If we look at information from Nepal Demographic and Health Survey (NDHS) 2001, the percent prevalence for underweight and wasted children of under-five years of age are 48.3 and $9.6 \%{ }^{8}$ Around $50 \%$ of the under five children are stunted ${ }^{8}$ and NDHS 2006 reveals that the percent prevalence for underweight and wasted children of under five years of age are $39 \%$ and $13 \% .{ }^{9}$ Forty nine percent of the under five children are stunted. ${ }^{9}$ Similarly, NDHS 2011 shows that the percent prevalence for stunting, underweight and wasting children for under five years of age are $41 \%, 29 \%$ and $11 \%$ respectively. ${ }^{10}$ Looking at these figures we can say that rapid decline is not observed in wasting and slight decline in underweight and stunting can be seen.

Childhood undernutrition existed in various degrees in different ecological zones and developmental regions of Nepal. Various factors may play the role of predictor variables while explaining the state of undernutrition. Based on the Human Development Index (HDI) Siraha district was found average level of other plain districts of Nepal. ${ }^{11}$

The Musahar community, in Terai Nepal, is socially and economically one of the most marginalized communities in Nepal and they are poorest amongst poor. The Musahar community falls under the category of the Dalit. The Musahars, they are famous as named by "rat eaters". It is considered the worse of the Dalit groups, the untouchables, which are the most segregated communities in Nepal. They are discriminated for their skin colour, religion, and traditions. They belongs the Hindu religion. Considering the low progress of health and socio-economic indicators, this community was selected for the study. This study was focused to assess the nutritional status of under-five (12-59) months children and to find out the factors associated with childhood undernutrition.

\section{Methods}

The present study was a community based cross sectional study carried out in urban Siraha district of Nepal among children aged 12-59months from January to April 2016 in Musahar community. Ethical approval was taken from Institutional Ethics Committee, K.S. Hegde Medical Academy, Nitte University, India. ${ }^{12}$ Written consent was obtained from each respondent after explaining the objectives and methods of the study. Children aged between 12 to 59 months and who belongs to Musahar community was included and Child with physical disability, ill, not staying with mothers and absent during the visit were excluded from the study. The objectives of the study was 
to assess the nutritional status of children aged $12-59$ months and to identify the factors associated with the nutritional status of the above study population. Considering the prevalence of under nutrition as $50 \%$ with $95 \%$ confidence interval and a $5 \%$ margin of error, sample size for the study was calculated by using cross sectional formula for finite population. ${ }^{13}$

$$
\mathrm{n}=\mathrm{NZ} \mathrm{Z}^{2} \mathrm{P}(1-\mathrm{P}) \mathrm{d}^{2}(\mathrm{~N}-1)+\mathrm{Z}^{2} \mathrm{P}(1-\mathrm{P}) \text { where } \mathrm{N}=746
$$

Total calculated sample size was 254. Simple random sampling method was applied to identify the required sample size. Out of all urban areas (Lahan municipality, Asanpur Golbazar municipality, Mirchaiya municipality and Siraha municipality) of Siraha district: first of all, the list of children name having aged 12-59months was taken from Female Community Health Volunteers (FCHV). Total numbers of children having aged 12-59months were 746. Random numbers were generated in Microsoft Excel the sample was obtained, after which those children were located with the assistance and details provided by the Female community health volunteers (FCHV).

A pre-tested semi structured questionnaire was used for collecting data from mother regarding socio-economic status, demographic information, health seeking practice, feeding practices and knowledge. Anthropometric data of the children was collected using standard instruments such as infantometer, stadiometer, weighing scale, and MUAC measuring tape. Pretesting was done in 25 samples in Lahan Municipality in Musahar community and some modification on question order and necessary filter options were added to the questionnaire. Questionnaire was translated in to local language

\section{Weight measurement}

The weight was taken using a digital weighing scale (UNICEF No.S0141021) and recorded to the nearest $0.01 \mathrm{~kg}$. The scales were checked for accuracy before taken to the field.

\section{Height measurement}

The children height and length was measured with a Stadiometer (UNICEF No.S0114520) and Infantometer (UNICEF No.S0114530) respectively and was recorded to the nearest $0.1 \mathrm{~cm}$. The length was taken in a lying position for less than 25 months children and height was taken in standing position for more than 24 months children. All children were measured barefoot, and without caps or hairdo.

\section{Mid upper arm circumference (MUAC)}

MUAC was measured in centimetres, to the nearest $0.1 \mathrm{~cm}$, using standard UNICEF MUAC measuring tapes (UNICEF No.S0145620). For malnutrition cases found: Each child that was found with severe acute malnutrition $(<115 \mathrm{~mm}$ MUAC) was referred to the closest health facility or to the FCHV.

\section{Age}

An event calendar was used to state the age as accurate as possible. Age was written down with "day/month/year" and "age in months". The Nepali date was converted into English date. Analysis was carried out at three levels. Data entry was done in Microsoft excel. Calculation of z-score was done by using software WHO ANTHRO v3.2.2. Further data analysis was done by using SPSS 16.0 software.

a. Univariate Analysis: descriptive analysis for all predictors and outcome variables.

b. Bivariate Analysis: Chi square test was used to find association between predictors and outcome variables. c. Multivariate Analysis: the significant variables ( $p$-value $<0.05$ ) observed in bivariate analysis were included in multivariate analysis.

Logistic regression model was applied to examine independent associations between explanatory variables and binary dependent variables. Chi-square test was applied to test the logistic regression model for goodness of fit.

For validation of this study, Relevant questionnaire was taken from NDHS for developing questionnaire based on study objectives and variables, using related and relevant available standard questionnaire with necessary modification in the local context. Age of child was calculated by using their date of birth date. Birth date was asked with mother and verified cross checking with immunization if it is available.

For reliability of this study, Data collected with the support from the community health workers. Weighing machine was checked frequently every fifth child by using $2 \mathrm{~kg}$ standard weight. Data was checked for errors and omissions on same day in the field and the consistency of data was maintained.

\section{Results}

Total 255 samples were collected for the study. Final analysis carried out on 255 samples. This represents $100 \%$ sample coverage. Table 1 shows the mean weight of children is $12 \mathrm{~kg}$ with 2.89 SD. Minimum and maximum weight is $6 \mathrm{~kg}$ and $19 \mathrm{~kg}$ respectively, with a range of 13 . The mean height of children is $91 \mathrm{~cm}$ with $10.61 \mathrm{SD}$. Minimum and maximum height is $55 \mathrm{~cm}$ to $108 \mathrm{~cm}$ with a range of 53. Mean age of children is 35 months with 14.05 SD. Minimum and maximum age is 12 months to 59 months with a range of 47 .

Table I According to NDHS, prevalence of under-nutrition in Nepal

\begin{tabular}{llll}
\hline & \multicolumn{2}{l}{ Undernutrition Status } & \\
\cline { 2 - 4 } & Stunting (\%) & Underweight (\%) & Wasting (\%) \\
\hline NDHS 200I & 50 & 48.3 & 9.6 \\
NDHS 2006 & 49 & 39 & 13 \\
NDHS 20II & 41 & 29 & 11 \\
\hline
\end{tabular}

In order to scrutinize the prevalence of child malnutrition, weightfor-height Z-score (WHZ), weight-for-age Z-score (WAZ), and height-for-age Z-score (HAZ) were used. The result of the survey proved that out of 255 children under-five (12-59)months of age, $21 \%$, $36 \%$, and $47 \%$ were malnourished as measured by WHZ (wasting), WAZ (underweight), and HAZ (stunting) scores, respectively (Table 2 ). Whereas the prevalence of severe wasting, severe underweight and severe stunting were found to be $9 \%, 12 \%$ and $20 \%$ respectively. The average height-for-age Z-scores, weight-for-height Z-score and weight-for-age $\mathrm{Z}$-score for the children are $-1.52,-0.36$ and -1.1 respectively (Table 3 ).

Similarly underweight or wasting is $40 \%$, stunting or wasting were $57 \%$ and stunting and underweight were $60 \%$. At least one of undernutrition children was $65 \%$. Only underweight, only stunting and only wasting children were $7 \%, 24 \%$ and $4 \%$ respectively. $16 \%$, $22 \%$ and $11 \%$ children were under the both undernutrition indicators (underweight \& wasting), (underweight \& wasting) and (wasting $\&$ stunting) respectively and $10 \%$ of children were found under the all undernutrition indicators (Underweight \& Stunting \& Wasting). Normal children were found $35 \%$ who were not under the any of the undernutrition indicators. 
Table 2 Frequency distribution of weight, height and age $(\mathrm{N}=255)$

\begin{tabular}{llll}
\hline Statistics & Weight in KG & Height/Length in CM & Age in month \\
\hline Mean & 12 & 91 & 35 \\
Std. Deviation & 2.89 & 10.61 & 14.05 \\
Range & 13 & 53 & 47 \\
Minimum & 6 & 55 & 12 \\
Maximum & 19 & 108 & 59
\end{tabular}

Table 3 Distribution of children, according to WHO classification of malnutrition $(\mathrm{N}=255)$

\begin{tabular}{|c|c|c|c|c|c|c|c|}
\hline \multirow{2}{*}{ Types } & \multirow{2}{*}{$\begin{array}{l}\text { Severe } \\
\mathbf{N}\end{array}$} & Moderate & Total & \multicolumn{4}{|c|}{ Mean Z score } \\
\hline & & $\%$ & $\mathbf{N}$ & $\%$ & $\mathbf{N}$ & $\%$ & \\
\hline Wasted $(<-2 S D)$ & 23 & 9 & 31 & 12 & 54 & 21 & $-0.36 \pm 1.88$ \\
\hline Stunted $(<-2 S D)$ & 51 & 20 & 68 & 27 & 119 & 47 & $-1.52 \pm 1.74$ \\
\hline Underweight $(<-2 S D)$ & 31 & 12 & 60 & 24 & 91 & 36 & $-I . I \pm|.4|$ \\
\hline
\end{tabular}

Prevalence of under-nutrition according to MUAC measurement shows that higher proportion $14 \%(n=36)$ of children had severe malnutrition, and nearly $6 \%$ children had moderate malnutrition whereas $11.5 \mathrm{~cm}$ cut off point for severe malnutrition. The bivariate analysis was carried out for the socio-demographic variables, educational and occupational status, health service utilization, feeding practice and morbidity against the major malnutrition indicators i.e. stunting, wasting and underweight. It is evident from the calculation that there is no significance obtained for the indicator-underweight against any of the above mentioned variables. Hence the bivariate analysis for only the stunting and wasting indicator are described below (Table 4).

From the Table 4, it is clearly evident that there is a significant association found among the sex, age of the child and monthly income of family with respect to stunting. Female children are 1.316 [COR, $0.807-2.146]$ times lesser risk than males for stunting. Aged of 24 to 36 months of children is 2.19 [COR, 1.08 - 4.451] times less risk for stunting than less than 24 months children. In the case of monthly income, NRs 11 to 15 thousand earning families are 0.419 [COR, $0.218-0.804$ ] and more than 19 thousand earning families are 0.466 [COR, 0.229 - 0.948] times high risk for stunting than those earning less than 11 thousand NRs per months. Those children whose father's having international employment are at 0.062 [COR, 0.005-0.76] time's high risk for stunting than formal employment. Children born through assisted type of delivery are 0.222 [COR, $0.060-0.816$ ] times high risk for stunting with respect to normal delivery.

Sex of the child had a significant association with wasting. Female prevalence of wasting is more than that in male, prevalence of wasting is $14 \%$ in male and $40 \%$ in female. Female children are 0.43 [COR, 0.221-0.843] times high than males for wasting.

For multi-variate analysis only the indicator stunting was considered. The factors which are considered for analysis are Gender, age of the child, monthly income of family, father's occupation and type of delivery. Underweight and wasting indicators were not considered as there were no statistically significant values obtained (Table 5).

The table is obtained by using binary logistic regression model for multivariate analysis. Adjusted odds ration statistically significant for 24 to 36 age group, formal employment and farmer of child's father occupation, and normal and caesarean type of delivery of child in prevalence of stunting. Age group 24 to 36 months children were found 0.25 [OR, $0.111-0.561]$ times high risk for stunting than 48 to 60 age group children. Similarly International employed father's children were found 0.092 [AOR, 0.010 - 0.857] times and 0.033 [AOR, 0.002 - 0.515] times less risk for stunting than farmer and formal employment fathers child. And Assisted born children were found 0.069 [AOR, 0.007 - 0.660] times and 0.18 [AOR, 0.043 $0.752]$ times less rick for stunting than caesarean and normal children respectively. 
Table 4 Stunting among under five children according to various variables $(\mathrm{N}=255)$

\begin{tabular}{|c|c|c|c|c|c|}
\hline Determinants & Stunting & $\%$ & Chi- square value & P-value & COR $95 \%$ for $\mathrm{Cl}$ \\
\hline \multicolumn{6}{|l|}{ Sex } \\
\hline Male (104) & 57 & 54.8 & & \multirow{3}{*}{$0.031 *$} & 1 \\
\hline \multirow{2}{*}{ Female (I5I) } & \multirow{2}{*}{62} & \multirow{2}{*}{41.06} & 4.677 & & 1.316 \\
\hline & & & & & {$[0.807-2.146]$} \\
\hline \multicolumn{6}{|l|}{ Age of the Child } \\
\hline$<24$ months $(64)$ & 31 & 48.43 & & \multirow{7}{*}{$0.009 *$} & I \\
\hline \multirow{2}{*}{24 to 36 months $(70)$} & \multirow{2}{*}{21} & \multirow{2}{*}{30} & & & 2.19 \\
\hline & & & & & [1.08-4.45I] \\
\hline \multirow{2}{*}{36 to 48 months (65) } & \multirow{2}{*}{36} & \multirow{2}{*}{55} & 11.577 & & 0.757 \\
\hline & & & & & {$[0.379-1.5 \mid 2]$} \\
\hline \multirow{2}{*}{48 to 60 months (56) } & \multirow{2}{*}{31} & \multirow{2}{*}{55} & & & 0.758 \\
\hline & & & & & {$[0.369-1.556]$} \\
\hline
\end{tabular}

\section{Monthly income of family in thousand}

\begin{tabular}{|c|c|c|c|c|c|}
\hline Less than II (75) & 25 & 33 & & & 1 \\
\hline II to I5 (79) & 43 & 54 & & & $\begin{array}{l}0.419 \\
{[0.218-0.804]}\end{array}$ \\
\hline 15 to $19(45)$ & 22 & 49 & 7.949 & $0.047^{*}$ & $\begin{array}{l}0.523 \\
{[0.245-1.114]}\end{array}$ \\
\hline More than $19(56)$ & 29 & 52 & & & $\begin{array}{l}0.466 \\
{[0.229-0.948]}\end{array}$ \\
\hline
\end{tabular}

\section{Father's Occupation}

\begin{tabular}{|c|c|c|c|c|c|}
\hline Formal employment (9) & 3 & 33 & & & I \\
\hline Daily labour (I0I) & 45 & 44.5 & & & $\begin{array}{l}0.622 \\
{[0.147-2.627]}\end{array}$ \\
\hline Self Employment/business (I5) & 10 & 44.5 & 10.08 & $0.039 *$ & $\begin{array}{l}0.25 \\
{[0.43-1.443]}\end{array}$ \\
\hline Farmer (I2I) & 53 & 43.8 & & & $\begin{array}{l}0.643 \\
{[0.153-2.685]}\end{array}$ \\
\hline International Employment (9) & 8 & 88 & & & $\begin{array}{l}0.062 \\
{[0.005-0.76]}\end{array}$ \\
\hline Type of Delivery & & & & & \\
\hline Normal (234) & 105 & 44.87 & & & I \\
\hline Caesarean (7) & 3 & 42.8 & 6.069 & $0.048 *$ & $\begin{array}{l}1.085 \\
{[0.238-4.957]}\end{array}$ \\
\hline Assisted (14) & 11 & 78.57 & & & $\begin{array}{l}0.222 \\
{[0.060-0.816]}\end{array}$ \\
\hline
\end{tabular}

*Significant, $\mathrm{COR}$, crude odds ratio; $\mathrm{Cl}$, confidence interval 
Table 5 Binary logistic regression model for demographic variables for Stunting

$\mathrm{AOR}$, adjusted odds ratio; $\mathrm{Cl}$, confidence interval *Significant

\begin{tabular}{|c|c|c|c|}
\hline Determinants & Percent & P-value & AOR (Cl-95\%) \\
\hline \multicolumn{4}{|l|}{ Sex } \\
\hline Male (104) & 54.8 & 0.056 & $\mathrm{I} .733[0.986-3.045]$ \\
\hline Female(I5I) & 41.06 & & I \\
\hline \multicolumn{4}{|l|}{ Age of the child } \\
\hline$<24$ months $(64)$ & 48.43 & 0.131 & 0.545 [0.247-I.199] \\
\hline 24 to 36 months $(70)$ & 30 & $0.00 I^{*}$ & $0.250[0.1 \mathrm{II}-0.56 \mathrm{I}]$ \\
\hline 36 to 48 months $(65)$ & 55 & 0.599 & $0.812[0.375-1.76 I]$ \\
\hline 48 to 60 months $(56)$ & 55 & & 1 \\
\hline \multicolumn{4}{|c|}{ Monthly income of family in thousand } \\
\hline Less than II (75) & 33 & 0.104 & $0.485[0.203-I .160]$ \\
\hline II to I5 (79) & 54 & 0.384 & $1.421[0.644-3.137]$ \\
\hline 15 to $19(45)$ & 49 & 0.933 & $0.963[0.40-2.321]$ \\
\hline More than $19(56)$ & 52 & & I \\
\hline \multicolumn{4}{|l|}{ Father's occupation } \\
\hline Formal employment (9) & 33 & $0.015^{*}$ & $0.033[0.002-0.515]$ \\
\hline Daily labour (I0I) & 44.5 & 0.66 & $0.118[0.012-1.154]$ \\
\hline Self Employment/business (I5) & 44.5 & 0.327 & $0.280[0.022-3.559]$ \\
\hline Farmer (I2I) & 43.8 & $0.036 *$ & $0.092[0.010-0.857]$ \\
\hline International Employment (9) & 88 & & 1 \\
\hline \multicolumn{4}{|l|}{ Type of delivery } \\
\hline Normal (234) & 44.87 & $0.019 *$ & $0.18[0.043-0.752]$ \\
\hline Caesarean (7) & 42.8 & $0.02 *$ & $0.069[0.007-0.660]$ \\
\hline Assisted (14) & 78.57 & & $\mathrm{l}$ \\
\hline
\end{tabular}

\section{Discussion}

This study was carried out to find the proportion of under-nutrition and associated factors in children aged 12 to 59months in Musahar community of urban Siraha district of Nepal. Here prevalence of malnutrition was to be found in three major indicators of malnutrition on basis of $\mathrm{Z}$ score of Height for age, Weight for height, Weight for age indicate as stunting, wasting, and underweight respectively. The major findings of the study are discussed here briefly.

In present study prevalence of stunting, wasting and underweight among under-five year children has been found 47, 21, and 36 percent respectively. This present study shows higher prevalence of stunting, wasting, and underweight than NDHS 2011 (41\%, 11\%, and 29\% respectively). ${ }^{10}$ Similar study in central rural Terai region, Nepal by Yadav $^{13}$ has shown lower prevalence than this study where wasting, stunting and underweight of children less than 3years was $31.1 \%$, $42.3 \%$ and $45 \%$ respectively except stunting. ${ }^{14}$

This study found that the prevalence of severe wasted and wasted were $9 \%$ and $12 \%$ respectively which are higher prevalence in severe wasting and wasting than the Eastern Terai that severely wasted and wasted among the children were $2.2 \%$ and $10.3 \%$ respectively reported in NDHS, 2011. ${ }^{10}$ Present study revealed that prevalence of severe stunting and stunting status of children were $20 \%$ and $27 \%$ which are higher prevalence of severe stunting, among the children in Eastern Terai that are $10.5 \%$ and $31.4 \%$ respectively reported in NDHS, $2011 .{ }^{10}$ This Study found that prevalence of severely underweight and underweight in children were $12 \%$ and $24 \%$ which are greater than that in eastern terai region where it is $5.6 \%$ and $24 \%$ respectively as reported in NDHS, 2011. ${ }^{10}$ 
The present study showed the higher prevalence of undernutrition was in female children (16\% wasted, $24 \%$ stunted and $22 \%$ underweight) as compared to male children ( $6 \%$ wasted, $22 \%$ stunted, and $13 \%$ underweight). The different result was shown in NDHS 2011 where male versus female was (12\% wasted, $41 \%$ stunted, and $30 \%$ underweight verses $10 \%$ wasted, $40 \%$ stunted, and $28 \%$ underweight in males and females respectively). ${ }^{10}$ However, the prevalence of stunting was higher among the females than in males. Similar finding was obtained from the survey done among less than 5years old Burmese refugee children, in Thailand. ${ }^{15}$

Prevalence of stunting was found high among the children whose mother had more children. This might be because in such family having many children there is partition of food, and all the children do not get equal attention and care. Colostrum feeding is one of the important determinants of nutritional status. But in this study no significant association was found between the colostrum feeding and nutritional status of the children. However, the relationship between colostrum feeding and underweight status was nearly significant as p-value obtained was 0.053 .

No association was found between the type of family, number of children, PNC, ANC and nutritional status of the children. However, the prevalence of malnourished children was found highest among the joint family as there was greater numbers of joint family children in the sample size.

The multivariate results revealed that 24 to 36 months of age children's nutrition was better for the nutritional status of children than the 48 to 59 months of age children. Higher the age of children significantly reduced the risk of stunting. The occupation of child's father independently influenced the nutritional status of children. The results of multiple linear regression showed that international employment can reduce $9 \%$ of stunting in children than the children whose father is a farmer.

The present study found that percentage who initiated breastfeeding within one hour of birth (58.3\%) was higher to previous findings from the Eastern Terai $(46.8 \%)$ and national level $(44.5 \%) .{ }^{10}$ The proportion of mothers who initiated breastfeeding within one hour of birth was higher in the present study compared to studies from Asia (31\%) and Africa (47\%). ${ }^{16}$ In a country, where undernutrition is high, appropriate breastfeeding practices are especially important. There are several possible explanations for high levels of breastfeeding and exclusive breastfeeding in Nepal. First, high levels of breastfed children might be due to public campaigns which aim to educate the mothers about infant and young child feeding practices. Second, mothers might be knowledgeable about child care because they have visited the Female Community Health Volunteers (FCHVs) or other health services. The FCHVs supports the women during pregnancy and gives advice about child health. ${ }^{10}$ Third reason being women decides to breastfeed because it is culturally accepted and valued. A survey from Makwanpur district in Nepal found that grandmothers supported early initiation of breastfeeding. ${ }^{17}$ At last, lack of money might encourage the mother to breastfeed the child because she cannot find any other way to feed the child.

Some of the findings of this study cannot be generalized to the mountainous and Terai (plain land) regions of Nepal due to socioeconomic and cultural differences between them. The socio-economic status of the people in our study area is worse than that of other parts of Nepal therefore the prevalence of malnutrition among these group would be high than that expected in other areas of the country.

\section{Conclusion}

This study demonstrated that undernutrition continues to be a serious problem in the Musahar community. At least suffered from one of undernutrition children were $65 \%$ where as the $10 \%$ children were suffered from all three undernutrition. According to Classification for assessing severity of malnutrition by prevalence ranges among children under 5years of age, the stunting, wasting and underweight rate were classified as very high. ${ }^{17}$ Stunting and underweight increased with age. The difference in sex was found in stunting where boys had higher chance of being stunting than the girls among 24-36month aged child. Child's father occupation played an important role in lowering the risk of chronic malnutrition (stunting) and underweight status among the children of less than 5years of age group. The result of this study indicated that the children of less than 24months had 2.19 times higher risk of suffering from chronic malnutrition (stunting).

This study has limitation of being representative of only urban Siraha district area and hence cannot be generalized for the entire population.

\section{Acknowledgements}

The authors would like to express our authentic gratefulness to all respondents who had provided valuable information and kind cooperation in our research project. Similarly, we extend our sincere gratitude to Department of Public Health, K.S. Hegde Medical Academy, Nitte University, Mangalore, India for the financial support and the community health worker who interviewed the mothers.

\section{Conflict of interest}

The author declares no conflict of interest.

\section{References}

1. Glewwe P, Miguel EA. The Impact of Child Health and Nutrition on education in less developed countries. In: Paul Schultz T, John S, editors. Hand book of Development Economics. Oxford, UK; 2007. p. 3561-3606.

2. Collins S, Dent N, Binns $P$, et al. Management of severe acute malnutrition in children. Lancet. 2006;368(9551):1992-2000.

3. Black RE, Allen LH, Bhutta ZA, et al. Maternal and child undernutrition: global and regional exposures and health consequences. Lancet. 2008;371(9608):243-260.

4. UNICEF. The State of World Children: Child Survival. USA: The United Nations Children's Emergency Fund; 2008.

5. WHO. Global Health Observatory (GHO) data. Switzerland: World Health Organization; 2016.

6. Shills ME, Young VR. Modern nutrition in health and disease. USA: Lea and Febiger; 1998.

7. Ministry of Health and Population. Nepal Demo-graphic and Health Survey. Nepal: New ERA; 2001

8. Ministry of Health and Population. Nepal Demo-graphic and Health Survey. Nepal: New ERA; 2006.

9. Ministry of Health and Population. Nepal Demo-graphic and Health Survey. Nepal: New ERA; 2011.

10. Nepal: Central Bureau of Statistics; 2011.

11. Karna A. Ethnographic study of Musahar community with emphasis on female group in Saptari district. Nepal: Tribhuvan University; 2008. 
12. Daniel WW. Biostatistics: A Foundation for Analysis in the Health Sciences. 7th ed. USA: John Wiley \& Sons; 1999.

13. Yadav DK, Gupta N, Shrestha N. An assessment of nutritional status of children less than 3 years in rural areas of Mahottari district of Nepal. IJMRHS. 2014;3(3):597-603.

14. Faraj N. Nutritional status of fewer than 5 year old Burmese Refugee children in Thailand. USA: University of Hawaii; 2005.
15. Janevic T, Petrovic O, Bjelic I, et al. Risk factors for childhood malnutrition in Roma settlements in Serbia. BMC Public Health. 2010;10(1):509.

16. UNICEF. Tracking progress on child and maternal nutrition. USA: United Nations Children's Fund; 2009.

17. WHO. Global Database on Child Growth and Malnutrition. Switzerland: World Health Organisation; 2016. 